\title{
Effect of Borax and Boric Acid on Thermal and Flammability Properties of Rice Husk Reinforced Recycled HDPE Composite
}

\begin{abstract}
By C. D. C. Dolotina ${ }^{*} \&$ Luis Maria T. Bo-ot ${ }^{ \pm}$
Studies show Rice Husk $(R H)$ and plastic appear viable in the production of a composite material. Flammability is a crucial parameter that limits multiple applications of such materials. Borax (BX) and Boric Acid (BA) have been used for wood and coating products, continually proving to be decent fire retardant agents in wood and plastic composites. In this study, the aim is to develop, test and investigate the thermal and flammability properties of $R H$ reinforced Recycled High-Density Polyethylene (rHDPE) integrated with Maleic Anhydride Polyethylene (MAPE) as a binding agent, with Borax (BX) and Boric Acid (BA) as a fire retardant agent. $R H$ was impregnated with $B X$ and $B A(1: 1)$ solution at 2,3 , and $4 \%$ weight concentration and oven-dried after seven days at $105^{\circ} \mathrm{C}$ for 24 hours. Only an average of 43 wt\% of BX and BA remains after the impregnation process. Flammability test results show that adding $R H$ to the composite enhanced flame retardancy compared to the pure rHDPE while adding MAPE as a binding agent makes the composite more flammable. Composite with $B X$ and $B A$ showed significant improvement in flame retardant properties by reducing the horizontal burning rate by $26 \%$ for $3 \%$ weight and $46 \%$ for $5 \%$ weight of MAPE. Thermogravimetric analyses exhibit an increase in the thermal stability by adding $R H$ to reinforce $r H D P E$ than pure $r H D P E$ and further augmented by the integration of $B X$ and $B A$.
\end{abstract}

Keywords: rice husk, recycled high-density polyethylene, thermal, flammability

\section{Introduction}

Rice Husk (RH) has been gaining attention as reinforcement in thermoplastic materials. Given the excellent compatibility between RH and the base polymer, RH would be an excellent option (Chand et al. 2010). Like any other natural fiber material, RH is hydrophilic and would result in poor compatibility and adhesion with the hydrophobic thermoplastic (Panthapulakkal et al. 2005). Silica, a siliconcellulose membrane in the outer surface of RH is attributed to its weak adhesion. Purifying RH from silica may result in better adhesion that may well eliminate the beneficial contribution of silica in the composite. Another way of solving this matter is by integrating a binding agent (Panthapulakkal et al. 2005, Hong et al. 2016, Yang et al. 2005). RH should be dried before processing, as it absorbs moisture that weakened mechanical properties (De Deus et al. 2005).

\footnotetext{
*Instructor, College of Engineering and Geo-Sciences, Caraga State University, Philippines.

${ }^{ \pm}$Professor, College of Architecture, University of the Philippines, Philippines.
} 
In comparison with inorganic-filler reinforced composite, $\mathrm{RH}$ has low $\mathrm{CO}_{2}$ emission with little to no toxic by-products when burnt, and has reasonable strength and stiffness (Kim et al. 2007, Yang et al. 2006a). As compared to other wood-based materials, RH composite has high resistance to biological attack, excellent termite resistance, and better dimensional stability under moist conditions (Kim et al. 2007).

Polyethylene (PE) and polypropylene (PP) have been the primarily used thermoplastic for processing RH composite (Panthapulakkal et al. 2005, Yang et al. 2004, 2005, 2006a, 2006b, Zhao et al. 2009, Najafi and Khademi-Eslam 2011, Kim et al. 2007, Aminullah et al. 2010, Rosa et al. 2009a). Recently, polyvinyl alcohol (PVA) and polyvinylchloride (PVC) have also been explored in creating RH reinforced composite (Arora et al. 2012).

Integrating binding agents have been studied in manufacturing $\mathrm{RH}$ reinforced plastic composite. Maleic anhydride polyethylene (MAPE) on RH/PE composites significantly improves the mechanical and physical properties, with the best properties at $6 \mathrm{wt} \%$ (Yang et al. 2005, Chen et al. 2015, Ab Ghani et al. 2014, Ghofrani 2011, Tong et al. 2014). Using maleic anhydride polypropylene as a binding agent improves tensile mechanical and physical properties of the composite, with the best properties at $5 \mathrm{wt} \%$ (Yang et al. 2005, Kim et al. 2007, Aminullah et al. 2010, Rosa et al. 2009b, Czél and Kanyok 2007). Scanning electron microscopy (SEM) micrographs indicate that using a binding agent improves interfacial adhesion in the composite (Yang et al. 2005, Aminullah et al. 2010, Rosa et al. 2009b, Ab Ghani et al. 2014, Ghofrani 2011).

On the other hand, fire retardant Borax (BX) and Boric Acid (BA) together denoted in this paper as BX+BA, had been utilized in wood treatment and had been studied in manufacturing fiber-reinforced composite. A study of physical properties shows that the presence of fire retardant $\mathrm{BX}+\mathrm{BA}$ decreases the water absorption by $50-80 \%$ in the urea-formaldehyde sawdust composite (Nagieb et al. 2011). The addition of the binding agent up to $4 \mathrm{wt} \%$ improved the waterresistance of the wood plastic composite (Ayrilmis et al. 2012). A BX+BA compound could enhance the decay resistance of wood plastic composite that may be attributed to its high moisture exclusion efficiency ( $\mathrm{Wu}$ and $\mathrm{Xu}$ 2014). The redistribution of $\mathrm{BX}+\mathrm{BA}$ in commercial cellulosic insulation due to vibration was investigated, and the study shows that the mass loss from cellulosic insulation is negligible when the temperature is below $70{ }^{\circ} \mathrm{C}$ at any relative humidity and air exchanges rate from 1.0 to 2.0 volumes per hour (Chiou and Yarbrough 1990).

The study on mechanical properties also exhibits that the increase of fire retardant concentration decreases bending strength in urea-formaldehyde sawdust (Nagieb et al. 2011). Tensile strength and flexural strength also decrease as BX+BA increase in the wood plastic composite (Ayrilmis et al. 2012, Wu and Xu 2014). BA treatment reduced static bending strength, compression strength, and slitting strength perpendicular to grain wood laminated beech veneer lumber (Colakoglu et al. 2003). Studies show that samples with BX provided better mechanical properties compared to those samples with BA in wood-flour plastic composite (Donmez Cavdar et al. 2015). BX had relatively more positive values on impregnation and heat treatment of oak wood (Percin et al. 2015). 
Flammability properties of RH plastic composite without fire retardant are closely related to RH loading. Studies show improved flame retardance with the increasing content of RH (Zhao et al. 2009, Bilal et al. 2014). The enhancement was due to the formation of a silica ash layer as a result of the combustion of $\mathrm{RH}$ that shields the remaining part of the composite for heat and oxygen leading to slow spread of flame of the composite (Zhao et al. 2009, Arora et al. 2012, Bilal et al. 2014). MAPE, as the binding agent, did not play a significant role in the heat release rate of the composite. Moreover, a slight decrease in values was observed with the increased loading of MAPE (Wu and Xu 2014).

A study using BX+BA shows that the addition of fire retardant decreases the burning rate in a wood plastic composite (Altuntaş et al. 2017). Another paper showed that the reduction of the burning rate was around $50 \%$ compared to the control sample on wood flour filled high-density polyethylene composite (Donmez Cavdar et al. 2015). These can be attributed to the wood becoming difficult to ignite, and more oxygen is needed to burn the treated materials, which is consistent with the effect of BX and BA compounds from a protective layer of compact black char (Donmez Cavdar et al. 2015). BA was shown to slow down flame during burning, hindering the attainment of high-temperature values, and also increased the flame collapse time (Karaağaçlıoğlu and Çelik 2012). BA has little effect on flame spread; however, higher char yield is produced in the samples with BA (Donmez Cavdar et al. 2015). BX exhibits better performance for restraining the heat release rate, while $\mathrm{BA}$ performs better on smoke suspension and the total amount of heat release. Furthermore, BX+BA aided to reduce the toxic gas production, especially in reducing the insufficient combustion and decreasing the $\mathrm{CO}$ production on $\mathrm{BX}+\mathrm{BA}$ treated bamboo filament (Yu et al. 2017). The best results could be attained with the ideal proportion of (1:1) of $\mathrm{BX}+\mathrm{BA}$ (Yu et al. 2017, Nagieb et al. 2011).

Thermogravimetric analysis shows that pure plastic sample had a lower initial temperature and higher weight loss speed of thermal decomposition compared to the samples with fire retardant on wood plastic composite (Donmez Cavdar et al. 2015). The addition of $\mathrm{BX}+\mathrm{BA}$ improves thermal properties at high temperatures and could enhance the formation of char ( $\mathrm{Wu}$ and $\mathrm{Xu} 2014)$.

This experimental research thus aims to develop and test new products of RH reinforced rHDPE composite integrating MAPE as a coupling agent and fire retardant $\mathrm{BX}+\mathrm{BA}$, and investigate the effect of different $\mathrm{BX}+\mathrm{BA}$ treatments on flammability and thermal properties of the composite. Flammability performances of samples were studied according to UL 94 testing, and thermal stability was investigated using the ATSM E1131 "Standard test method for compositional analysis by thermogravimetry."

\section{Experimentation and Testing}

\section{Source of Materials}

RH was accumulated from a local rice milling plant at Ampayon, Butuan City, Philippines, without further grounding. While emptied bleach plastic bottles 
were collected from a local laundry shop at Nasipit, Agusan del Norte, Philippines. Fire retardants BX and BA were obtained from NECO Philippines, Incorporated. MAPE as compatibilizer was obtained from Shanghai Jianqiao Plastic Co., Ltd. in the name of NG1001. The MFI of MAPE was $1.5 \mathrm{~g} / 10 \mathrm{~min}$, with a density of 0.96 $\mathrm{g} / \mathrm{cm}^{3}$.

\section{Manufacturing Process}

Collected RH was oven-dried at $105{ }^{\circ} \mathrm{C} \pm 5{ }^{\circ} \mathrm{C}$ for 24 hours to reduce its moisture content and weight (W1) then sealed in a polyethylene bag to ensure its dryness before mixing with fire retardants BX and BA. Collected rHDPE in the form of bleach plastic bottles were cleansed to remove any residual liquid and dirt. Plastic bottles were then cut into small pieces and washed, rinsed, and soaked in warm water for 30 minutes to remove the liquid soap and sun-dried for 8 hours to attain its dryness.

BX and BA were diluted in distilled water at $80{ }^{\circ} \mathrm{C}$, after which the ovendried RH was submerged and mixed with the concentrations as shown in Table 1. After 24 hours of immersion, excess water was removed, and the impregnated RH with $\mathrm{BX} / \mathrm{BA}$ was conditioned at room temperature with $60 \%$ relative humidity for one week as shown in Figures $1 \mathrm{a}$ and $1 \mathrm{~b}$. After one week, the impregnated $\mathrm{RH} / \mathrm{BX} / \mathrm{BA}$ was oven-dried at $105^{\circ} \mathrm{C} \pm 5^{\circ} \mathrm{C}$ for 24 hours and weighed (W2).

Impregnated RH/BX/BA was mixed with rHDPE and MAPE by a two-roll mill machine with a back-roller temperature of $220{ }^{\circ} \mathrm{C}$ and a front roller temperature of $195{ }^{\circ} \mathrm{C}$. First, rHDPE was put into the rolling machine, where it reaches its stage of plasticity. Secondly, MAPE as a binding agent was added. Finally, impregnated RH/BX/BA was gently sprinkled into the rolling plastic as shown in Figures $2 \mathrm{a}$ and $2 \mathrm{~b}$.

Table 1. Proposed Formulation of RH Reinforced rHDPE Composite in Weight Percentage

\begin{tabular}{|l|c|c|c|c|c|}
\hline Sample No. & rHDPE & RH & MAPE & Borax & $\begin{array}{c}\text { Boric } \\
\text { Acid }\end{array}$ \\
\hline 1 & 100 & - & - & - & - \\
\hline 2 & 60 & 40 & - & - & - \\
\hline 3 & 58.20 & 38.80 & 3 & - & - \\
\hline 4 & 57.00 & 38.00 & 3 & 1 & 1 \\
\hline 5 & 56.40 & 37.60 & 3 & 1.5 & 1.5 \\
\hline 6 & 55.80 & 37.20 & 3 & 2 & 2 \\
\hline 7 & 57 & 38 & 5 & - & - \\
\hline 8 & 55.80 & 37.20 & 5 & 1 & 1 \\
\hline 9 & 55.20 & 36.80 & 5 & 1.5 & 1.5 \\
\hline 10 & 54.60 & 36.40 & 5 & 2 & 2 \\
\hline
\end{tabular}

Blended rHDPE/MAPE/RH/BX/BA was placed in a $203 \times 203 \times 4 \mathrm{~mm}$ thick stainless steel mold and molded by a Shinto compression molding machine with a temperature of $180{ }^{\circ} \mathrm{C}$ and a compression strength of $50 \mathrm{~kg} / \mathrm{cm}^{2}$ for 5 minutes. After 5 minutes, the composite was placed in a cool press machine with $50 \mathrm{~kg} / \mathrm{cm}^{2}$ 
for another 5 minutes and air-cooled before removing the finished product from the mold as shown in Figures $3 a$ and $3 b$. The composite sample as shown in Figure $4 \mathrm{a}$ and $4 \mathrm{~b}$, was air-dried for another two days and was cut according to the specific dimension required for material testing.

Figure 1. Impregnating Process: (a) RH Soaked in Fire Retardant Solution for 24 Hours and (b) Impregnated RH/BX/BA, After Removing Excess Water

(a)

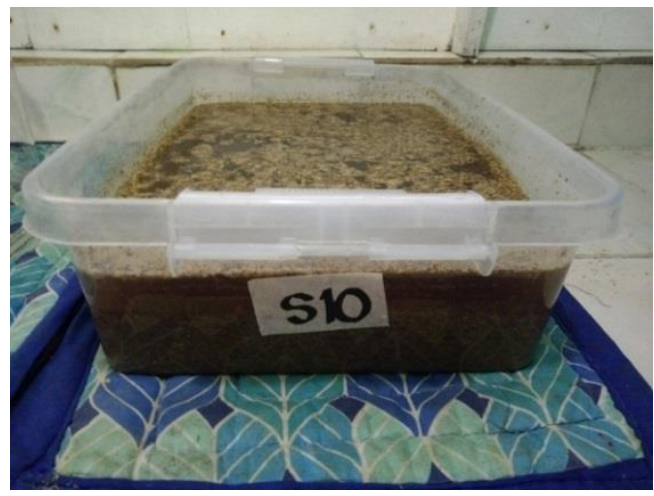

(b)

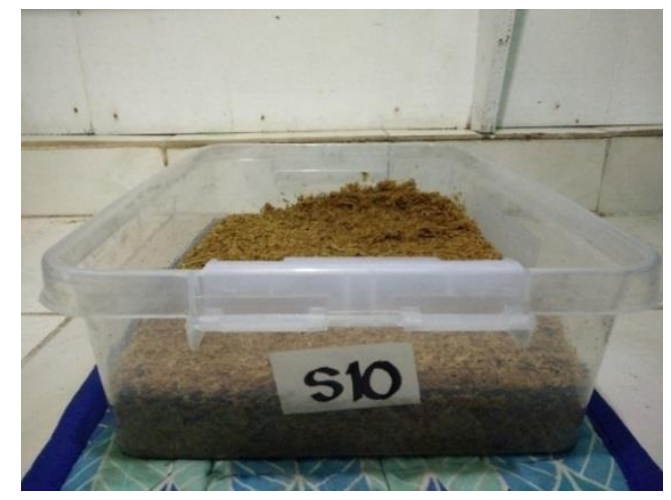

Figure 2. Reinforcing $r H D P E$ with $M A P E$ and Impregnated $R H / B X / B A:$ (a) Integrating MAPE on Plasticized $r H D P E$ at $200{ }^{\circ} \mathrm{C}$ (b) Adding $R H / B X / B A$ on Impregnated $r H D P E / M A P E$

(a)

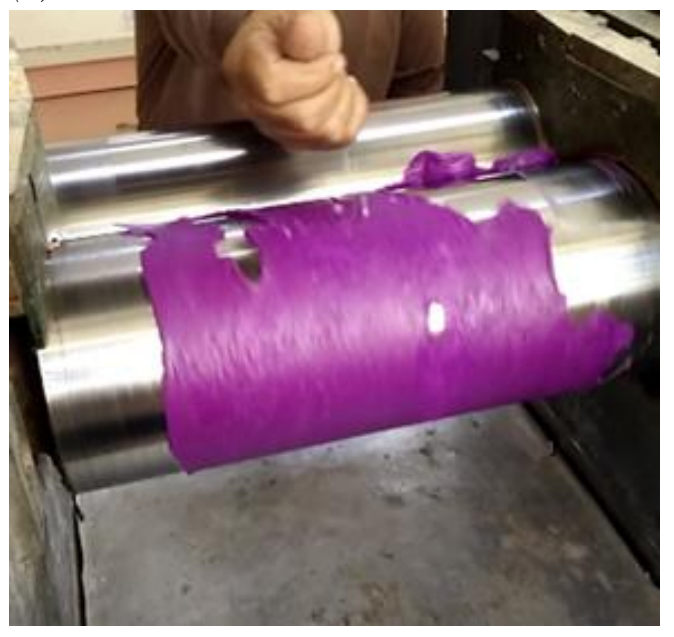

(b)

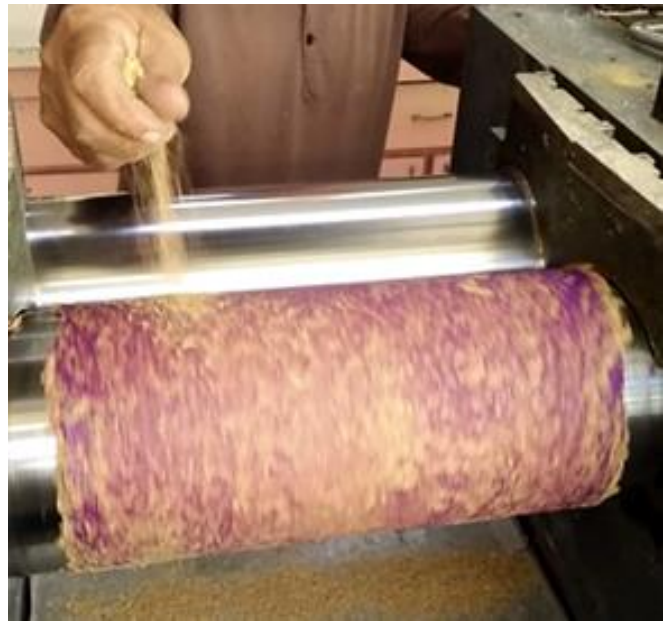


Figure 3. Compression Process: (a) Blended rHDPE/MAPE/RH/BX/BA in $203 \times 203 \times 4 \mathrm{~mm}$ Thick Stainless Steel Mold (b) Hot Compression Process of the RH Reinforced rHDPE Composite
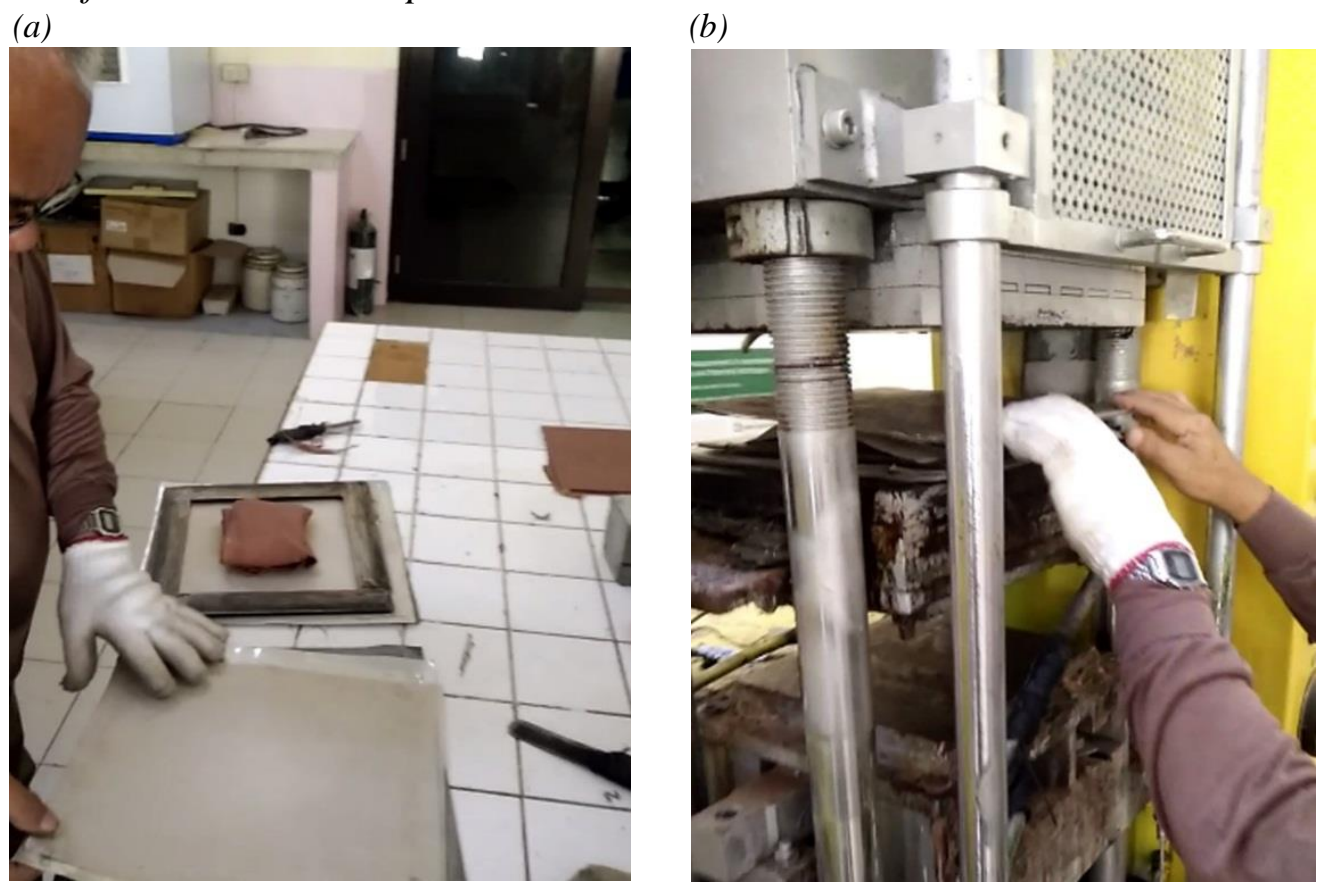

Figure 4. Finished Product of (a) Pure rHDPE and (b) RH Reinforced rHDPE Composite

(a)

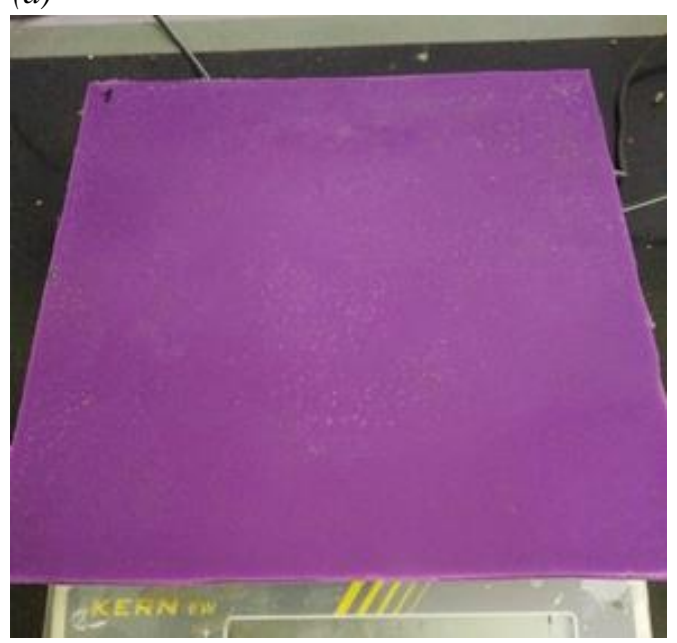

(b)

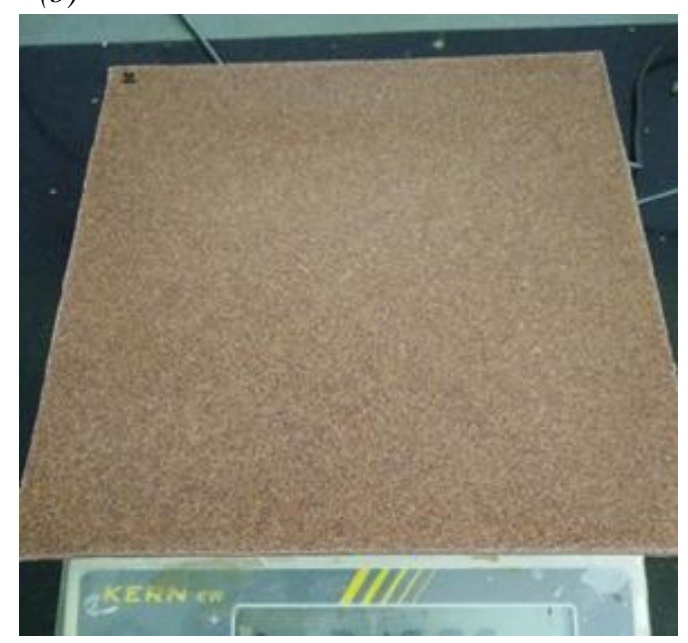

Sample 1 contains $100 \%$ of pure rHDPE as the controlled sample. Sample 2 contains RH reinforced rHDPE with 60\% rHDPE and 40\% RH. Samples 3 and 7 were integrated with MAPE as a binding agent, $3 \%$ weight of MAPE for sample 3, and 5\% weight of MAPE for sample 7. On the other hand, rHDPE and RH contents were retained at $60 \%$ weight of rHDPE and $40 \%$ weight of RH, minus the weight percentage of the binding agent MAPE. Samples 4, 5, and 6 were samples with $3 \%$ weight of MAPE and 1\%, $1.5 \%$, and $2 \%$ weight of fire retardant BX and BA, 
respectively. rHDPE and RH contents were retained at $60 \%$ weight of rHDPE and $40 \%$ weight of $\mathrm{RH}$, with the reduction of the weight percentage of MAPE and fire retardant BX and BA. Samples 8, 9, and 10 were samples with $5 \%$ weight of MAPE and $1 \%, 1.5 \%$, and $2 \%$ weight of fire retardant BX and BA, respectively. rHDPE and RH contents, on the other hand, were kept at $60 \%$ weight of rHDPE and $40 \%$ weight of $\mathrm{RH}$, excluding the weight percentage of MAPE and fire retardant $\mathrm{BX}$ and $\mathrm{BA}$.

\section{Impregnation of $R H$ with Fire Retardant $B X$ and $B A$}

Oven-dried RH was weighed (W1) and impregnated using a soaking method for 24 hours. Excess water was removed after 24 hours and was conditioned for one week. Subsequently, impregnated RH was oven-dried and weighed (W2) to determine the percentage weight gain (PWG) according to equation

$$
\text { PWG }(\%)=(\mathrm{W} 2-\mathrm{W} 1) \times 100 / \mathrm{W} 1
$$

where PWG is the percentage weight gain of the $\mathrm{RH}$ after the impregnation process, W1 is the weight of RH before impregnation, and W2 is the weight of RH after the impregnation process (Donmez Cavdar et al. 2015).

\section{UL 94 Testing}

The burning rate was investigated by the horizontal burning (HB) test according to UL 94 test standards using Atlas HVUL2 at the Department of Science and Technology, Taguig City, Philippines. Three specimens per sample were cut into $125 \times 13 \times 4 \mathrm{~mm}$ to be tested. The linear burning rate in millimeters per minute was calculated using the following equation:

$$
\mathrm{V}=60 \mathrm{~L} / \mathrm{t}
$$

where $\mathrm{V}$ is the horizontal burning in millimeters per minute from $25 \mathrm{~mm}$ to 100 mm benchmark. $\mathrm{L}$ is the damaged length in millimeters, and $\mathrm{t}$ is time in seconds (UL 94).

The longitudinal axis of the sample is mounted horizontally with its transverse axis at 45 degrees. The flame is applied on the free end for 30 seconds and removed, or as soon as combustion reaches the $25 \mathrm{~mm}$ benchmark. Time ( $\mathrm{t}$ ) and length of damage (L) are recorded as combustion travel from $25 \mathrm{~mm}$ mark up to $100 \mathrm{~mm}$ mark or as soon as it stops. The sample is classified as HB rated if the burning rate does not surpass the $40 \mathrm{~mm} / \mathrm{min}$ or if the fire self-extinguishes before the $100 \mathrm{~mm}$ reference point (UL 94).

\section{Thermal Analysis}

Thermal analysis of samples was performed according to ATSM E1131 using the TGA Q500 instrument at the Department of Mining, Metallurgical and Materials 
Engineering, University of the Philippines. Approximately 35 to $50 \mathrm{mg}$ per sample was tested at a heating rate of $10^{\circ} \mathrm{C} / \mathrm{min}$, from $28{ }^{\circ} \mathrm{C}$ to $650{ }^{\circ} \mathrm{C}$ under an oxygen atmosphere. Weight loss of samples was recorded continuously during the thermal decomposition process (ASTM E1131 - 08).

\section{Results and Discussion}

Impregnation Analysis

In Figure 5, it was observed that BX+BA was not entirely infused with $\mathrm{RH}$ in terms of weight after the impregnation process, thereby reducing the amount of $\mathrm{BX}+\mathrm{BA}$ on the actual composition. Data shows that sample number 4 has the highest percentage of absorption among the impregnated samples. Samples number 5 and 9 had the same absorption percentage, while sample number 6 is quite higher by $1 \%$ compared to sample number 10 . On average, only $43 \mathrm{wt} \%$ of fire retardants were absorbed after the impregnation process. Moreover, it has been observed that as fire retardant increases, the percentage of absorption decreases. The loss of weight of $\mathrm{BX}+\mathrm{BA}$ due to the impregnation process leads to the addition of rDHPE and $\mathrm{RH}$ in the actual composition, as shown in Table 2.

Figure 5. Percentage Weight Gain of $R H$ with $B X$ and BA Before and after Immersion

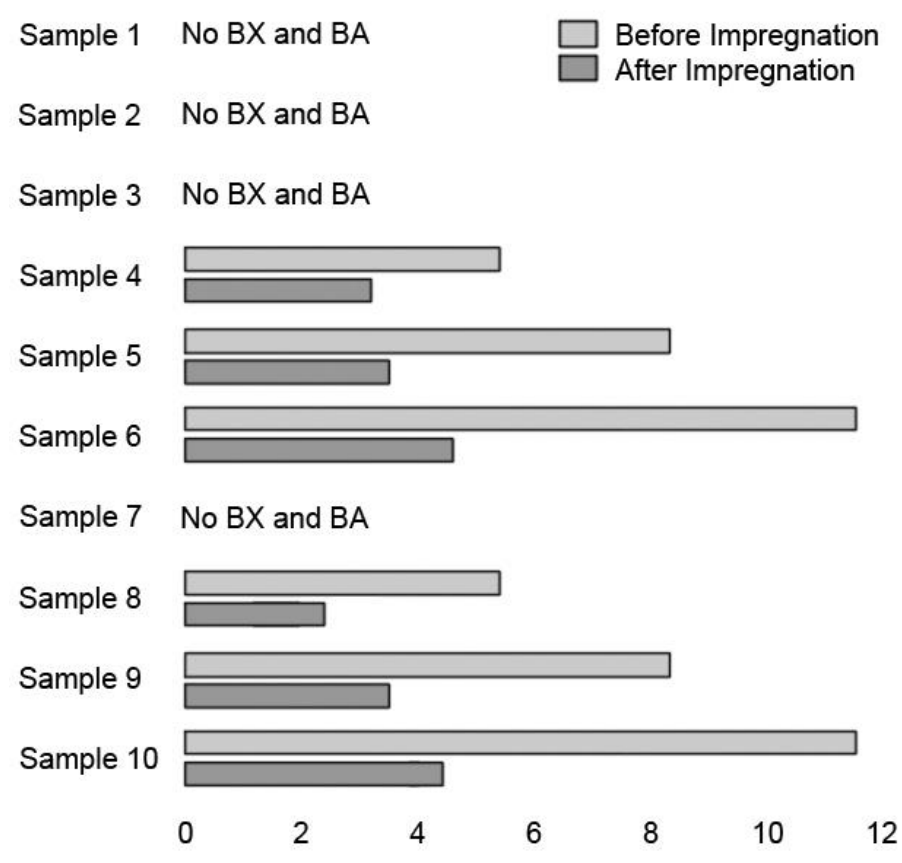


Table 2. Actual Formulation of RH Reinforced rHDPE Composite in Weight Percentage

\begin{tabular}{|l|c|c|c|c|c|}
\hline Sample No. & rHDPE & RH & MAPE & Borax & Boric Acid \\
\hline 1 & 100 & - & - & - & - \\
\hline 2 & 60 & 40 & - & - & - \\
\hline 3 & 58.20 & 38.80 & 3 & - & - \\
\hline 4 & 57.43 & 38.29 & 3 & 0.64 & 0.64 \\
\hline 5 & 57.38 & 38.26 & 3 & 0.68 & 0.68 \\
\hline 6 & 57.13 & 38.09 & 3 & 0.89 & 0.89 \\
\hline 7 & 57 & 38 & 5 & - & - \\
\hline 8 & 56.45 & 37.63 & 5 & 0.46 & 0.46 \\
\hline 9 & 56.21 & 37.47 & 5 & 0.66 & 0.66 \\
\hline 10 & 55.99 & 37.33 & 5 & 0.84 & 0.84 \\
\hline
\end{tabular}

\section{Flammability Studies}

The results of the UL 94 Horizontal Burning Rate are shown in Figure 6. Data show the average burning rate of specimens per sample. Samples with RH (sample 2) have a $6.03 \%$ burning rate reduction compared to the pure rHDPE material (sample 1) that could be attributed to the silica layer created during the combustion of RH that acts as a thermal barrier and heat sink between the fire and the sublayer of the composite (Bilal et al. 2014). The addition of Maleic Anhydride Grafted Polyethylene as a binding agent to the composite increases the burning rate by about $13 \%$ with $3 \mathrm{wt} \%$ on sample 3 and $32 \%$ with $5 \mathrm{wt} \%$ on sample 7 of MAPE compared to rHDPE with RH (sample 2).

Figure 6. UL 94 Horizontal Burning Rate in Millimeters per Minute

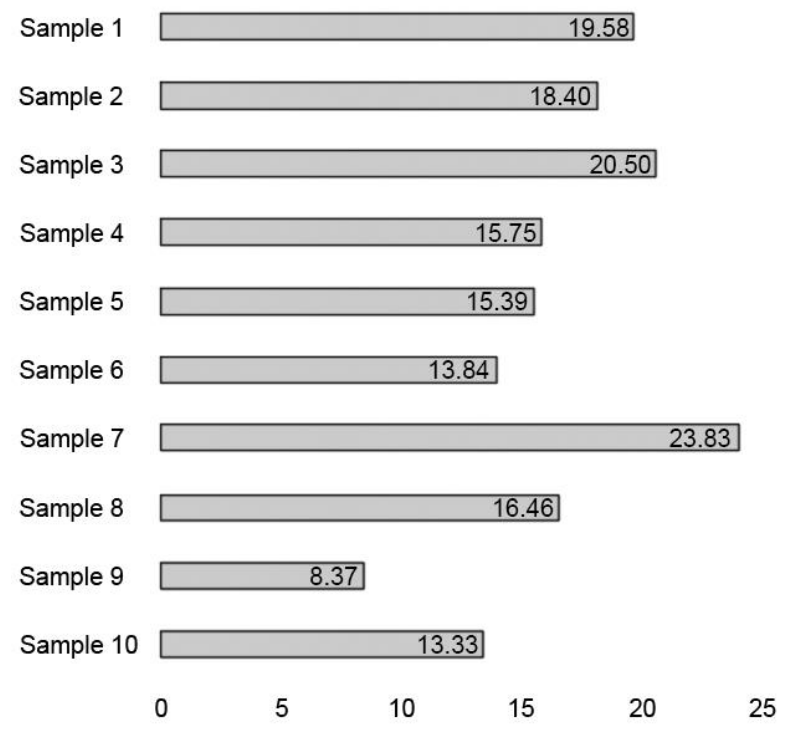

Even though $3 \mathrm{wt} \%$ of MAPE increases flammability by $13 \%$ compared to $\mathrm{RH}$ reinforced rHDPE (sample 2), the addition of $\mathrm{BX}+\mathrm{BA}$ to the composite enhances flame retardancy by reducing the burning rate of the material. Sample 4 
with $1.28 \mathrm{wt} \%$ of $\mathrm{BX}+\mathrm{BA}$ has $23 \%$, sample 5 with $1.36 \mathrm{wt} \%$ of $\mathrm{BX}+\mathrm{BA}$ has $24 \%$, and sample 6 with $1.78 \mathrm{wt} \%$ of $\mathrm{BX}+\mathrm{BA}$ has $32 \%$ burning rate reduction.

Incorporating $5 \mathrm{wt} \%$ of MAPE increases flammability by $32 \%$ compared to $\mathrm{RH}$ reinforced $\mathrm{rHDPE}$ (sample 2). However, the addition of $\mathrm{BX}+\mathrm{BA}$ to the composite significantly decreases the flammability by reducing the burning rate of the material. Sample 8 with $0.92 \%$ of BX+BA has $30 \%$, sample 9 with $1.32 \%$ of $\mathrm{BX}+\mathrm{BA}$ has $64 \%$, and sample 10 with $1.68 \%$ of $\mathrm{BX}+\mathrm{BA}$ has a $44 \%$ burning rate reduction.

Overall, the addition of fire retardant BX+BA to the composite significantly decreases flammability by reducing the burning rate by $26 \%$ (samples $4,5,6$ ) on average with $3 \mathrm{wt} \%$ of MAPE and about $46 \%$ (sample 8,9,10) on average with 5 wt $\%$ of MAPE. The findings further support that the addition of fire retardant $\mathrm{BX}+\mathrm{BA}$ is an excellent factor for the fire retardancy of the composite (Nagieb et al. 2011, Donmez Cavdar et al. 2015, Yu et al. 2017). MAPE as a binding agent that is known to improve fiber-matrix adhesion between RH and rHDPE and enhanced structural stability of the composite does not show positive enhancement on flame retardancy, as composite displays increased flammability as the amount of binding agent increases. The same was observed on the study of RH polyethylene composite with MAPE as a binding agent (Bilal et al. 2014). However, the addition of the fire retardant $\mathrm{BX}+\mathrm{BA}$ shows significant improvement on the flammability of the composite even with of the integration of binding agent. These may be attributed to the addition of fire retardant incorporation with the contribution of improving cross-linking between the RH and the fiber-matrix.

Figure 7 exhibits one of three specimens per sample after the horizontal burning test. Noticeably, all nine samples exhibit a char formation except sample 1 of the pure rHDPE sample. Char formation of the nine samples with RH is credited to the silica layer of RH formed during the combustion process. The silica ash shields the composite that hinders the oxygen supply from the heat, leading to a reduction of the spread of flame (Zhao et al. 2009). Furthermore, the addition of $\mathrm{BX}+\mathrm{BA}$ promotes carbon residue production and fire retardation during the combustion process (Zhao et al. 2009).

Figure 7. One of Three Specimens per Sample after the UL 94 Horizontal Burning Test

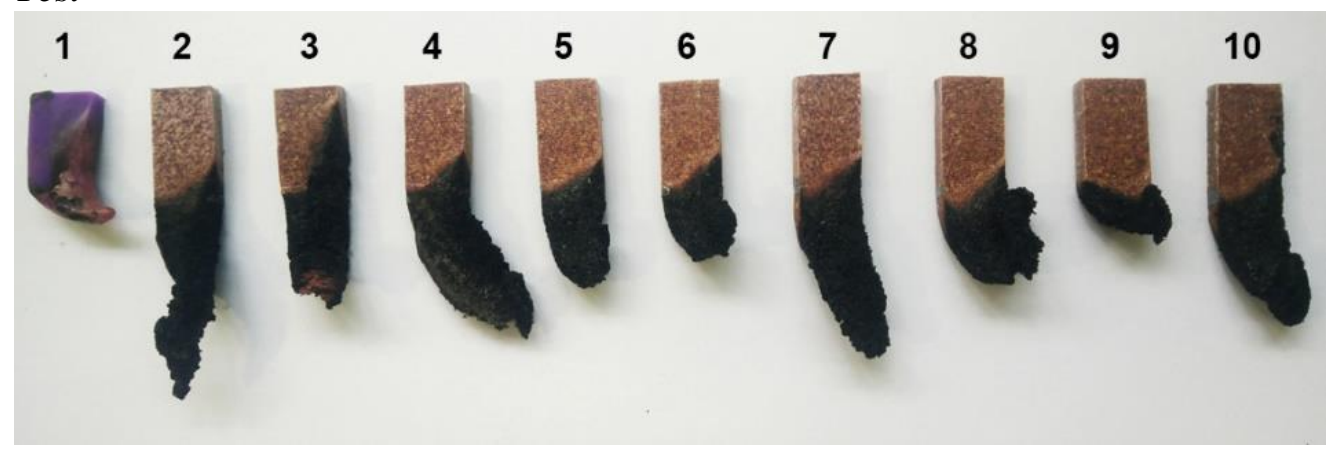

Figures $8 \mathrm{a}$ and $8 \mathrm{~b}$ show the actual horizontal burning test of the materials. Comparatively, pure rHDPE (Figure 8a) exhibits a material degradation as rHDPE 
gradually melts as the flame impinges on the specimen, while $\mathrm{RH}$ reinforced rHDPE (Figure $8 \mathrm{~b}$ ) displays a stable condition with char formation as it burned.

Figure 8. Horizontal Burning Test of (a) Pure rHDPE and (b) RH Reinforced rHDPE

(a)

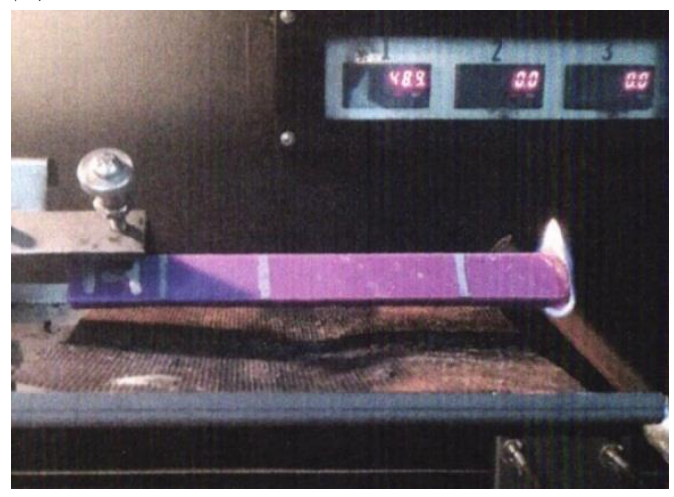

(b)

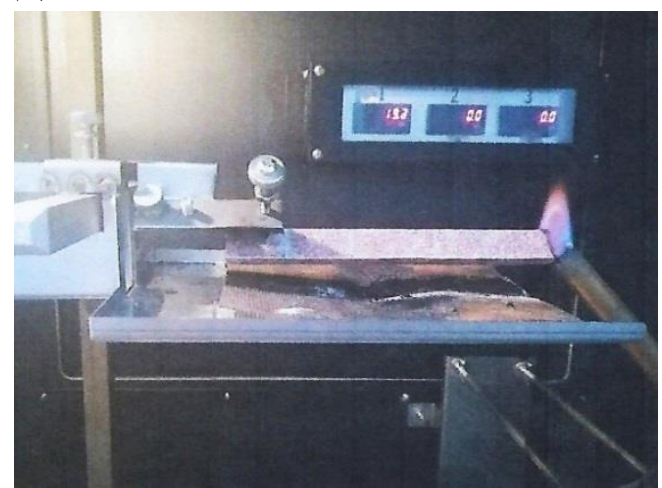

Figures 9a and 9b exhibit the actual horizontal burning test of the materials as the flame reached the $25 \mathrm{~mm}$ mark. Relatively, pure rHDPE (Figure 9a) shows a higher flame length corresponding to the highly flammable characteristics of the materials (Whiteley and Pan 1990). On the other hand, RH reinforced rHDPE composite (Figure 9b) presents a favorable condition than pure rHDPE with the evidence of char formation upon burning. The results further support that the flame retardancy mechanism was attributed to thermal protection and the transmission barrier produced by the silica layer created during the burning process (Zhao et al. 2009).

Figure 9. Horizontal Burning Test at $25 \mathrm{~mm}$ Benchmark of (a) Pure rHDPE and (b) $R H$ Reinforced rHDPE

(a)

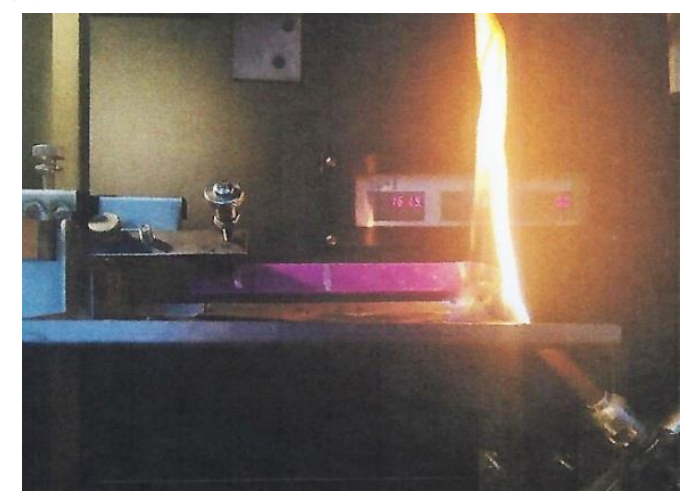

(b)

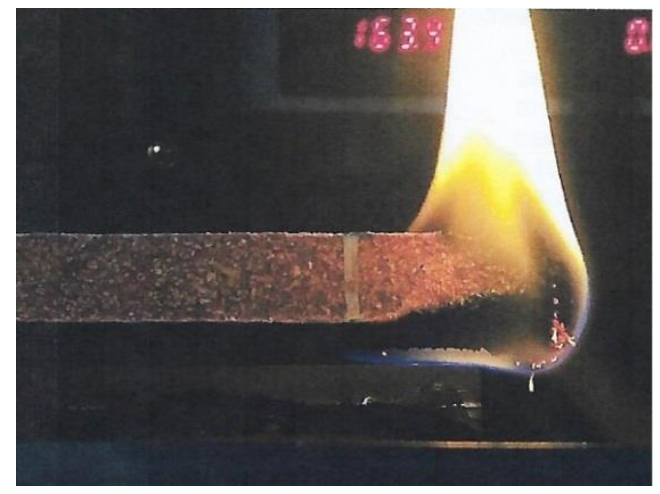

\section{Thermal Studies}

Figure 10 represents the thermal degradation of all samples at a heating rate of $10{ }^{\circ} \mathrm{C}$ per minute. Unlike rHDPE samples in the related literature (Zhao et al. 2009), sample 1 with pure rHDPE underwent a two-step degradation. The first 
weight loss was observed at around $325{ }^{\circ} \mathrm{C}$ to $335^{\circ} \mathrm{C}$ that loses $70 \%$ of its weight, followed by the second degradation process at around $415{ }^{\circ} \mathrm{C}$ to $445{ }^{\circ} \mathrm{C}$ as the weight reduces to $0.62 \%$. Second stage degradation could be attributed to impurities of the materials, as plastic bottles were cleansed without further purification. It is not manifest what might constitute such behavior; however, a study has reported that foreign materials may be present and the interactions with these impurities of these interactions may exhibit a positive or negative effect on thermal stability (Vásquez-Rendón and Álvarez-Láinez 2018).

Figure 10. TGA Curves of All Composite Samples at a Heating Rate of $10^{\circ} \mathrm{C}$ per Minute under Flowing Oxygen Atmosphere

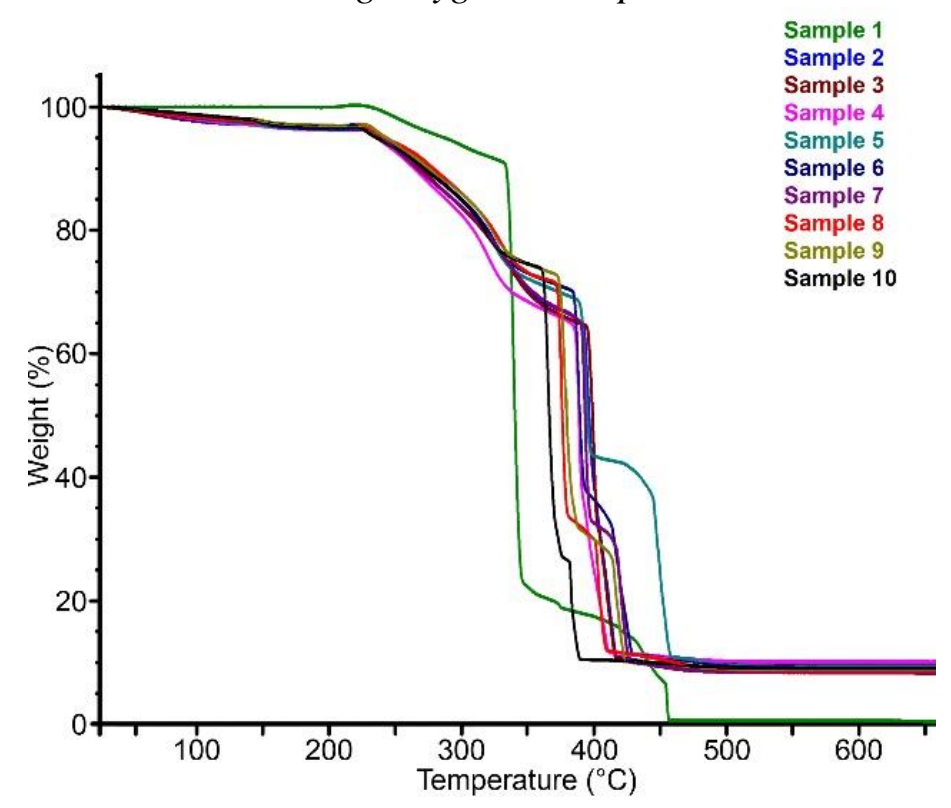

RH reinforced rHDPE (sample 2) underwent a three-stage degradation process; the first stage occurred in the range of $28{ }^{\circ} \mathrm{C}$ to $225{ }^{\circ} \mathrm{C}$ that measures about $4 \%$ weight loss that corresponds to the evaporation of moisture confined on the $\mathrm{RH}$. The second stage of weight reduction happens at $300{ }^{\circ} \mathrm{C}$ to $350{ }^{\circ} \mathrm{C}$ that corresponds to the decomposition of cellulose and hemicellulose components of $\mathrm{RH}$. The third stage of weight reduction occurs at $380{ }^{\circ} \mathrm{C}$ to $410{ }^{\circ} \mathrm{C}$, which corresponds to the decomposition of lignin and rHDPE with $10 \%$ weight retention represented by RH ash (Zhao et al. 2009). 
Figure 11. TGA Curves of Pure rHDPE Composite (Sample 1), 60\% rHDPE with 40\% RH (Sample 2), rHDPE/RH Composite with 3\% MAPE (Sample 3) and 5\% MAPE (Sample7)

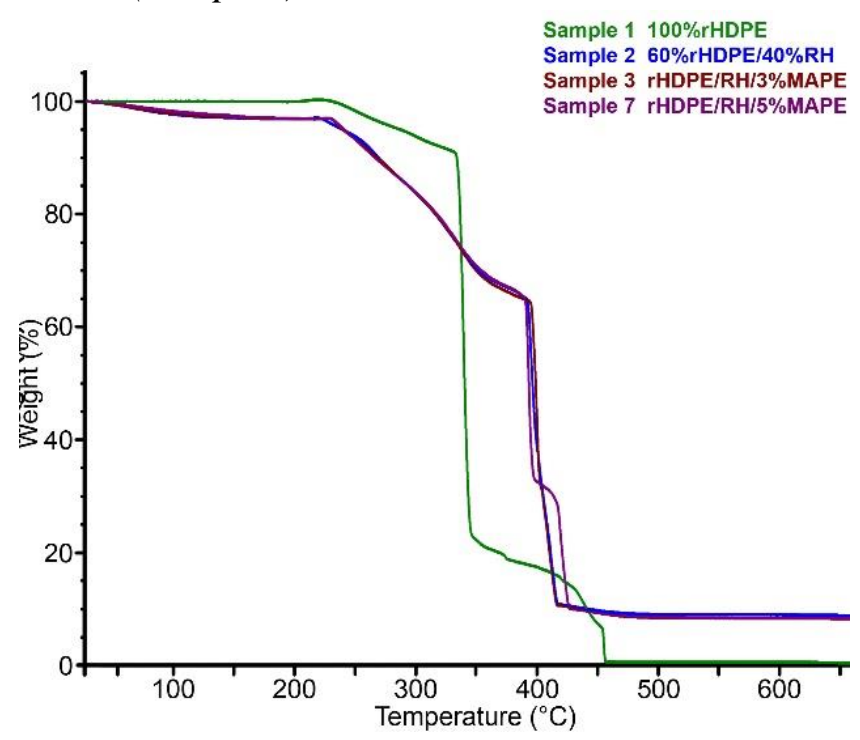

In Figure 11, it is seen that RH reinforced rHDPE composite with $3 \mathrm{wt} \%$ of MAPE (sample 3) does not exhibit any significant change in comparison to sample 2 without MAPE. However, increasing the binding agent to $5 \mathrm{wt} \%$ of MAPE (sample 7) exhibits another stage of the degradation process. Stage 3 of thermal decomposition happens at $380^{\circ} \mathrm{C}$ to $400{ }^{\circ} \mathrm{C}$, and stage 4 degradation follows at 410 ${ }^{\circ} \mathrm{C}$ to $430{ }^{\circ} \mathrm{C}$ with $9 \%$ weight retention. Thermal stability enhancement on sample 7 could be attributed to interfacial bonding improvement and compatibility between the $\mathrm{RH}$ and the matrix due to the treatment of the binding agent.

Figure 12. TGA Curves of rHDPE/RH with 3\%MAPE as a Binding Agent with the Different Fire Retardant Formulations

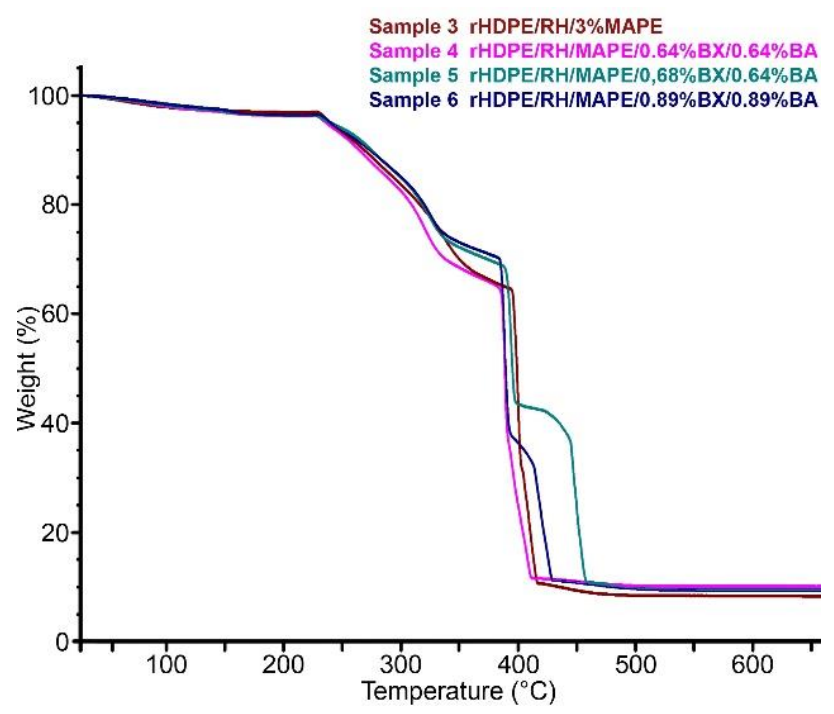


Figure 12 exhibits the TGA of sample 3 (RH composite without fire retardant), sample 4, sample 5, and sample 6 with different concentrations of fire retardant BX and BA with $3 \mathrm{wt} \%$ of MAPE. The figure exhibits a similar stage 1 degradation process and slightly different during the second stage of the process. Data also show that the sample with $3 \mathrm{wt} \%$ of MAPE without fire retardant (sample 3) is slightly better than sample 4 with $0.64 \mathrm{BX}+0.64 \mathrm{BA}$. Sample 5 with $0.68 \mathrm{BX}+$ $0.68 \mathrm{BA}$, on the other hand, shows excellent thermal stability with the new stage of degradation that occurred between $400{ }^{\circ} \mathrm{C}$ and $460{ }^{\circ} \mathrm{C}$ with $10 \mathrm{wt} \%$ weight retention in comparison to sample 6 with $0.89 \mathrm{BX}+0.89 \mathrm{BA}$ with higher fire retardant content. Thermal stability enhancement and the increase of weight retention are credited to the presence of BX that tends to reduce the flame spread (Zhao et al. 2009), and BA elevates the production of carbonaceous char layer resulting in flammability reduction (Intharapat et al. 2016).

Figure 13 shows the thermogravimetric analysis of sample 7 (RH composite without fire retardant), sample 8 , sample 9, and sample 10 with different concentrations of fire retardant BX and BA with $5 \mathrm{wt} \%$ of MAPE. All samples exhibit a similar stage 1 degradation process, with a variation in stage 2 decomposition process. Data reveals that even though sample 8, sample 9, and sample 10 with fire retardant exhibit an additional stage of thermal degradation, sample 7 with $5 \mathrm{wt} \%$ of MAPE without fire retardant agent performs better. The phenomenon could be attributed to interfacial adhesion between RH and rHDPE brought by the integration of MAPE as a binding agent of the composite under fire (Bilal et al. 2014).

Figure 13. TGA Curves of rHDPE/RH with 5\%MAPE as a Binding Agent with the Different Fire Retardant Formulations

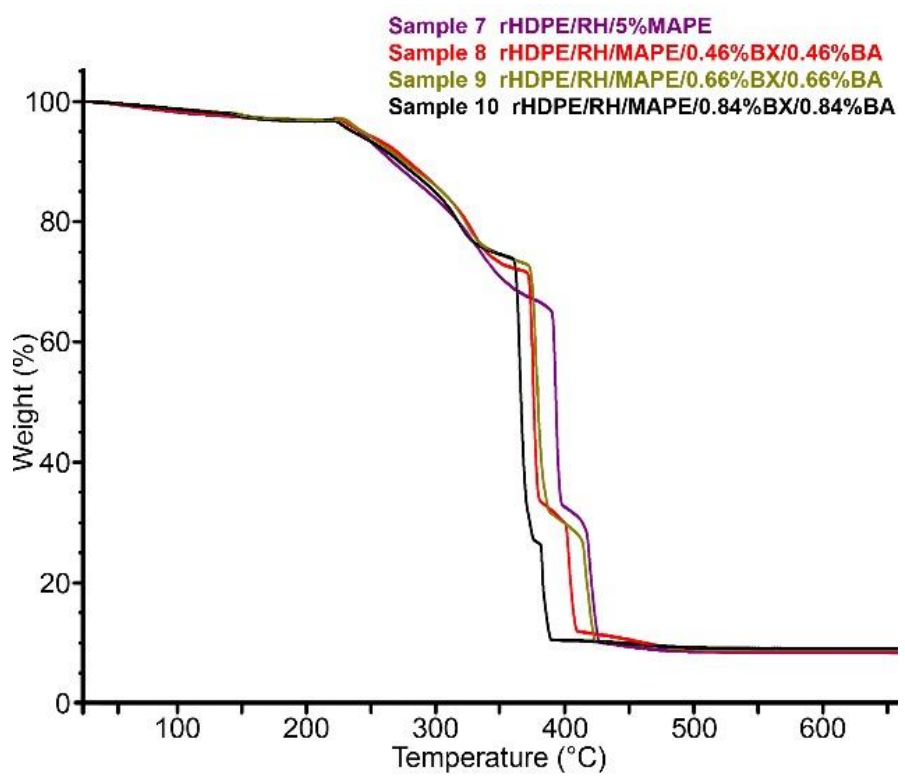


Figure 14. TGA Curves of Sample 6 (Top), Sample 9 (Bottom Left) and Sample 10 (Bottom Right) in Random Sampling

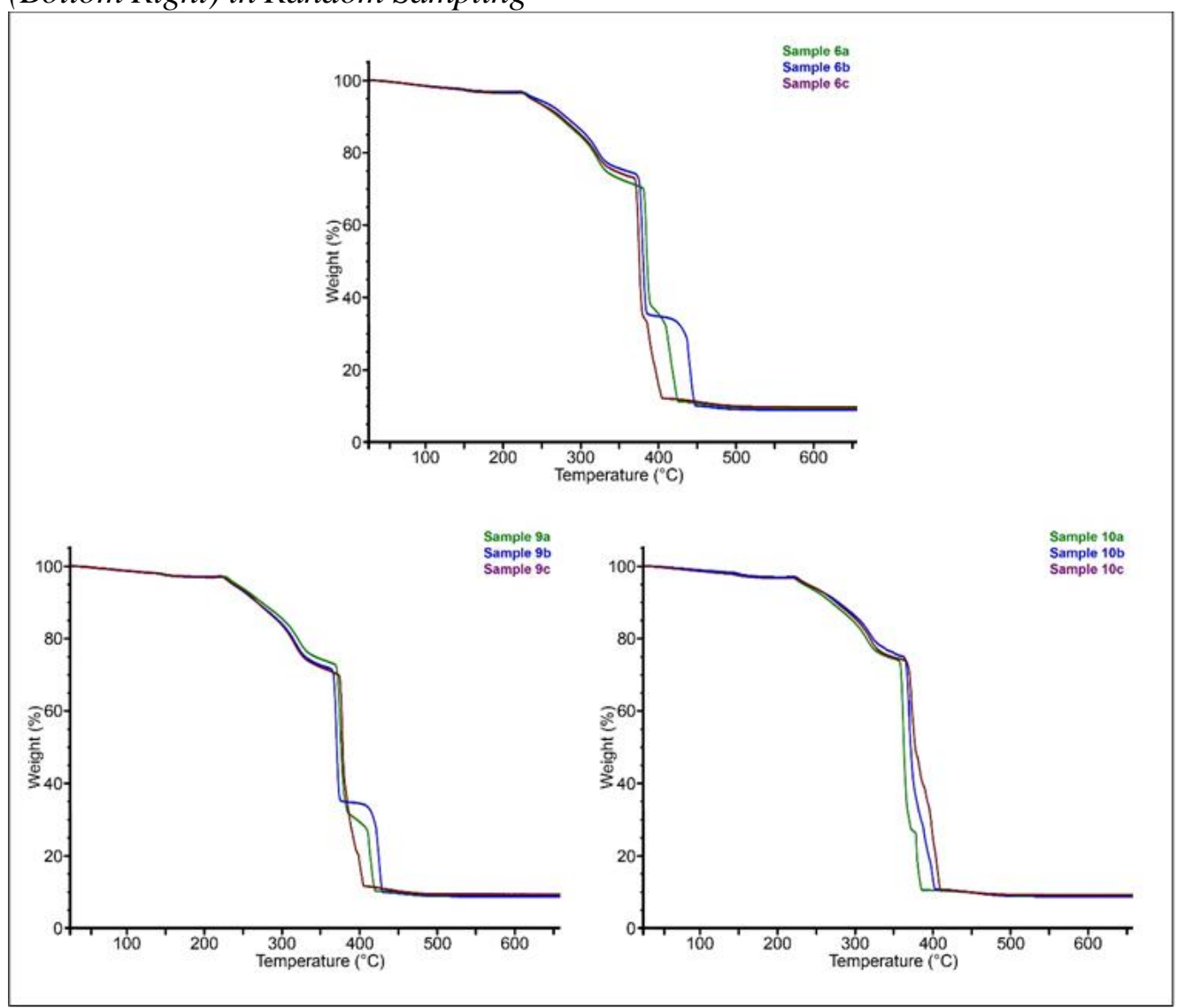

The top 3 samples on flammability were investigated on thermal stability are shown in Figure 14. It was evident that samples 6, 9, and 10 have similar stage 1 degradation with a little deviation on stage 2 as well as stage 3 decomposition. However, a significant variation was clearly exhibited on the stage 4 decomposition process that can be attributed to the integration of MAPE as a binding agent and fire retardant BX and BA. Comparatively, sample 6 with 3 wt $\%$ of MAPE as a bending agent performs better with a temperature range of $400{ }^{\circ} \mathrm{C}$ to $450{ }^{\circ} \mathrm{C}$ than samples 9 and 10 with $5 \mathrm{wt} \%$ of the binding agent with $380{ }^{\circ} \mathrm{C}$ to $430{ }^{\circ} \mathrm{C}$.

\section{Conclusions}

The impregnated RH with fire retardant BX and BA reinforced rHDPE was prepared successfully through twin roll mill and hot compression machine. Based on the UL 94 flammability test and ASTM E1131 thermogravimetry test results of the composite, the following observations were drawn.

On average, the impregnation process enabled the samples to absorb $43 \mathrm{wt} \%$ of fire retardant $\mathrm{BX}$ and $\mathrm{BA}$. Moreover, the percentage of absorption of the fire retardant decreases as the fire retardant increases. 
Flame retardancy of RH reinforced rHDPE was improved in comparison to the pure rHDPE composite. However, the integration of MAPE as a binding agent increases flammability by $13 \%$ on $3 \mathrm{wt} \%$ and $32 \%$ on $5 \mathrm{wt} \%$ of MAPE. The addition of fire retardant $\mathrm{BX}$ and $\mathrm{BA}$, on the other hand, enhances flame retardancy of the composite, which was clearly observed in the UL 94 horizontal burning test. On average, a reduction of $26 \%$ on burning rate with $3 \mathrm{wt} \%$, and $46 \%$ with $5 \mathrm{wt} \%$ of MAPE. The optimum composition for flammability is at $5 \mathrm{wt} \%$ of MAPE with $0.66 \% \mathrm{BX}$ and $0.66 \% \mathrm{BA}$.

The thermal stability of the composite was improved with the addition of RH compared to the pure rHDPE composite. The binding agent, MAPE, did not play a significant role in the thermal stability of the composite at $3 \mathrm{wt} \%$, but slightly improved and exhibited another stage of degradation at $5 \mathrm{wt} \%$. However, the addition of fire retardant BX and BA shows that samples with $3 \mathrm{wt} \%$ perform better than samples with $5 \mathrm{wt} \%$ of MAPE. Moreover, samples with $5 \mathrm{wt} \%$ without fire retardant exhibit better thermal stability than those with a fire retardant agent. Data show that the optimum composition for thermal stability is at $3 \mathrm{wt} \%$ of MAPE with $0.68 \%$ of BX and $0.68 \%$ BA.

Thus, $\mathrm{RH}$ performs as an effective ecological fire retardant in the composite, and the addition of BA and $\mathrm{BX}$ as non-organic fire retardant that further augment the fire retardancy of the composite makes it favorable in any applications where the fire is an essential parameter with its low flammable properties that will prevent fire hazards in order to protect life and property. We note however that UL 94 is only applicable for devices and appliances. We can explore the possibility of the composite as a candidate for building material like baseboard, moldings, fascia board, ceiling, and wall panel though this may require another testing like UL 263 or ASTM E119 (Kordosky et al. 2020, Amat et al. 2012).

\section{References}

Ab Ghani MH, Salleh MN, Chen RS, Ahmad S (2014) The effects of rice husk content on mechanical and morphological properties of recycled polymer biocomposites. American-Eurasian Journal of Sustainable Agriculture 8(4): 128-134.

Altuntaş E, Karaoğul E, Alma MH (2017) Effect of boron compounds on the thermal and combustion properties of wood-plastic composites. Turkish Journal of Forestry 18(3): 247-250.

Amat RC, Ibrahim NM, Rahim NL, Tajudin NSBA, Ahmad KR (2014) Fire resistance of biomass ash panels used for internal partitions in buildings. Procedia Engineering 53(Jan): 52-57.

Aminullah A, Syed Mustafa SJ, Nor Azlan MR, Mohd Hafizi N, Mohd Asri I, Rozman HD (2010) Effect of filler composition and incorporation of additives on the mechanical properties of polypropylene composites with high loading lignocellulosic materials. Journal of Reinforced Plastics and Composites 29(20): 3115-3124.

Arora S, Kumar M, Kumar M (2012) Flammability and thermal degradation studies of PVA/rice husk composites. Journal of Reinforced Plastic Composites 31(2): 85-93.

ASTM E1131 - 08. Standard test method for compositional analysis by thermogravimetry 1. ASTM International 2015: 6. 
Ayrilmis N, Akbulut T, Dundar T, White RH, Mengeloglu F, Buyuksari U, et al. Effect of boron and phosphate compounds on physical, mechanical, and fire properties of wood-polypropylene composites. Construction and Building Materials 33(Aug): 6369.

Bilal A, Lin RJT, Jayaraman K (2014) Optimisation of material compositions for flammability characteristics in rice husk/polyethylene composites. Journal of Reinforced Plastics and Composites 33(22): 2021-2033.

Chand N, Sharma P, Fahim M (2010) Tribology of maleic anhydride modified rice-husk filled polyvinylchloride. Wear 269(11-12): 847-853.

Chen RS, Ab Ghani MH, Ahmad S, Salleh MN, Tarawneh MA (2015) Rice husk flour biocomposites based on recycled high-density polyethylene/polyethylene terephthalate blend: effect of high filler loading on physical, mechanical and thermal properties. Journal of Composite Materials 49(10): 1241-1253.

Chiou N, Yarbrough DW (1990) Permanency of boric acid used as a fire retardant in cellulosic insulation. Energy and Buildings 14(4): 351-361.

Colakoglu G, Colak S, Aydin I, Yildiz UC, Yildiz S (2003) Effect of boric acid treatment on mechanical properties of laminated beech veneer lumber. Silva Fennica 37(4): 505-510.

Czél G, Kanyok Z (2007) MAgPP as an effective coupling agent in rice husk flour filled polypropylene composites. Materials Science Forum 537(Feb): 137-144.

De Deus JF, Monteiro SN, D’Almeida JRM (2005) Effect of drying, molding pressure, and strain rate on the flexural mechanical behavior of piassava (Attalea funifera Mart) fiber-polyester composites. Polymer Testing 24(6): 750-755.

Donmez Cavdar A, Mengelołlu F, Karakus K (2015) Effect of boric acid and borax on mechanical, fire and thermal properties of wood flour filled high density polyethylene composites. Measurement 60(Jan): 6-12.

Ghofrani M (2011) A study on rice-husk/recycled high density polyethylene composites their physical and mechanical properties. Environmental Sciences 9(1): 99-112.

Hong H, Li X, Liu H, Zhang H, He H, Xu H, et al. (2016) Transform rice husk and recycled polyethylene into high performance composites: using a novel compatibilizer to infiltratively enhance the interfacial interactions. Progress in Rubber, Plastics and Recycling Technology 32(4): 253-268.

Intharapat P, Nakason C, Kongnoo A (2016) Preparation of boric acid supported natural rubber as a reactive flame retardant and its properties. Polymer Degradation and Stability 128(Jun): 217-227.

Karaağaçlığlu İE, Çelik MS (2012) Effect of boric acid on fire retardant properties of compressed mineral added cellulosic insulators. In Proceedings of the XIIIth International Mineral Processing Symposium, 1-8. Bodrum, Turkey.

Kim HS, Lee BH, Choi SW, Kim S, Kim HJ (2007) The effect of types of maleic anhydride-grafted polypropylene (MAPP) on the interfacial adhesion properties of bio-flour-filled polypropylene composites. Composites Part A: Applied Science and Manufacturing 38(6): 1473-1482.

Kordosky AN, Drury MM, Quiel SE (2020) Structural fire resistance of partially restrained, partially composite floor beams, I: experiments. Journal of Constructional Steel Research 167(Apr): 105945.

Nagieb ZA, Nassar MA, El-Meligy MG (2011) Effect of addition of boric acid and borax on fire-retardant and mechanical properties of urea formaldehyde saw dust composites. International Journal of Carbohydrate Chemistry (Nov): 1-6.

Najafi A, Khademi-Eslam H (2011) Lignocellulosic filler/recycled HDPE composites: effect of filler type on physical and flexural properties. BioResources 6(3): 24112424. 
Panthapulakkal S, Law S, Sain M (2005) Enhancement of processability of rice husk filled high-density polyethylene composite profiles. Journal of Thermoplastic Composite Materials 18(5): 445-458.

Percin O, Sofuoglu SD, Uzun O (2015) Effects of boron impregnation and heat treatment on some mechanical properties of oak (Quercus petraea Liebl.) wood. BioResources 10(3): 3963-3978.

Rosa SML, Nachtigall SMB, Ferreira CA (2009a) Thermal and dynamic-mechanical characterization of rice-husk filled polypropylene composites. Macromolecular Research 17(1): 8-13.

Rosa SML, Santos EF, Ferreira CA, Nachtigalt SMB (2009b) Studies on the properties of rice-husk-filled-PP composites - Effect of maleated PP. Materials Research 12(3): 333-338.

UL 94. Tests for flammability of plastic materials for parts in devices and appliances. 2013. Available at: https://standardscatalog.ul.com/standards/en/standard_94_6.

Vásquez-Rendón M, Álvarez-Láinez ML (2018) Tailoring the mechanical, thermal, and fl ammability properties of high- performance PEI / PBT blends exhibiting dual-phase continuity. Polymer 154(76): 241-252.

Whiteley MJ, Pan WP (1990) A study of the flammability of chlorinated polyethylene under pyrolysis conditions. Thermochimica Acta 166(Sep): 27-39.

Wu GF, Xu M (2014) Effects of boron compounds on the mechanical and fire properties of wood-chitosan and high-density polyethylene composites. BioResources 9(3): 4173-4193.

Yang HS, Kim HJ, Son J, Park HJ, Lee BJ, Hwang TS (2004) Rice-husk flour filled polypropylene composites; mechanical and morphological study. Composite Structures 63(3-4): 305-312.

Yang HS, Kim HJ, Park HJ, Lee BJ, Hwang TS (2005) Effect of compatibilizing agents on rice-husk flour reinforced polypropylene composites. Composite Structures 77(1): $45-55$.

Yang HS, Kim HJ, Park HJ, Lee BJ, Hwang TS (2006a) Water absorption behavior and mechanical properties of lignocellulosic filler-polyolefin bio-composites. Composite Structures 72(4): 429-437.

Yang HS, Wolcott MP, Kim HS, Kim S, Kim HJ (2006b) Properties of lignocellulosic material filled polypropylene bio-composites made with different manufacturing processes. Polymer Testing 25(5): 668-676.

Yu L, Cai J, Li H, Lu F, Qin D, Fei B (2017) Effects of boric acid and/or borax treatments on the fire resistance of bamboo filament. BioResources 12(3): 5296-5307.

Zhao Q, Zhang B, Quan H, Yam RCM, Yuen RKK, Li RKY (2009) Flame retardancy of rice husk-filled high-density polyethylene ecocomposites. Composites Science and Technology 69(15-16): 2675-2681. 